\title{
Jauss
}

Journal of Al-Azhar University Engineering Sector

Vol.15, No. 57, October, 2020, 1030-1039

\section{FABRICATION OF AA6082/WC NANOCOMPOSITE BY FRICTION STIR PROCESSING AND OPTIMIZATION USING TAGUCHI APPROACH}

\author{
A. Mourad ${ }^{* 1}$, Amir A. Mahdy ${ }^{2}$, E.S. Mosa ${ }^{2}$ and A. Kandil ${ }^{2}$ \\ ${ }_{1}^{1}$ Intercairo company for Aluminum Industry, $6^{\text {th }}$ October,Giza,Egypt. \\ ${ }^{2}$ Mining, Metallurgy and Petroleum Engineering Department, Al- Azhar University, \\ Nasr City 11371, Cairo, Egypt. \\ *Corresponding Author E-mail: amoradsobhy@gmail.com
}

\begin{abstract}
:
Friction stir processing (FSP) is a novel solid-state technique based on the principle of friction stir welding. It is used for material processing in order to modify the microstructures and mechanical properties and to fabricate metal matrix composites. FSP has been successfully employed for fabrication of AA6082/ (6, 10, 14, and 18 vol. \% / WC) composite materials. Tungsten carbide nanoparticles with an average diameter of $50 \mathrm{~nm}$ were added as a reinforcement material. Tungsten carbide particles packed in a groove of width $(0.4,0.7,1$, and $1.3 \mathrm{~mm}$ ) and depth $5 \mathrm{~mm}$ to result in four different volume fractions. FSP experiment parameters like tool rotational/traverse speed, groove width, tool geometry, and number of passes were studied. The mechanical and wear behavior of composite material fabricated by FSP were investigated. The process parameters were optimized using the Taguchi analysis, at last, optimum values of corresponding tests are determined. The results were confirmed by further experiments. The results reveal that ultimate tensile strength, hardness and wear resistance of WC/A6082 nanocomposite are enhanced, compared to those of the AA6082 matrix, and Wear rate significantly decreased after a multi-pass.
\end{abstract}

KEYWORDS: Aluminum alloy 6082 Matrix Composite, Friction Stir Processing, Tungsten Carbide Particles, Wear Rate, and Taguchi Analysis.

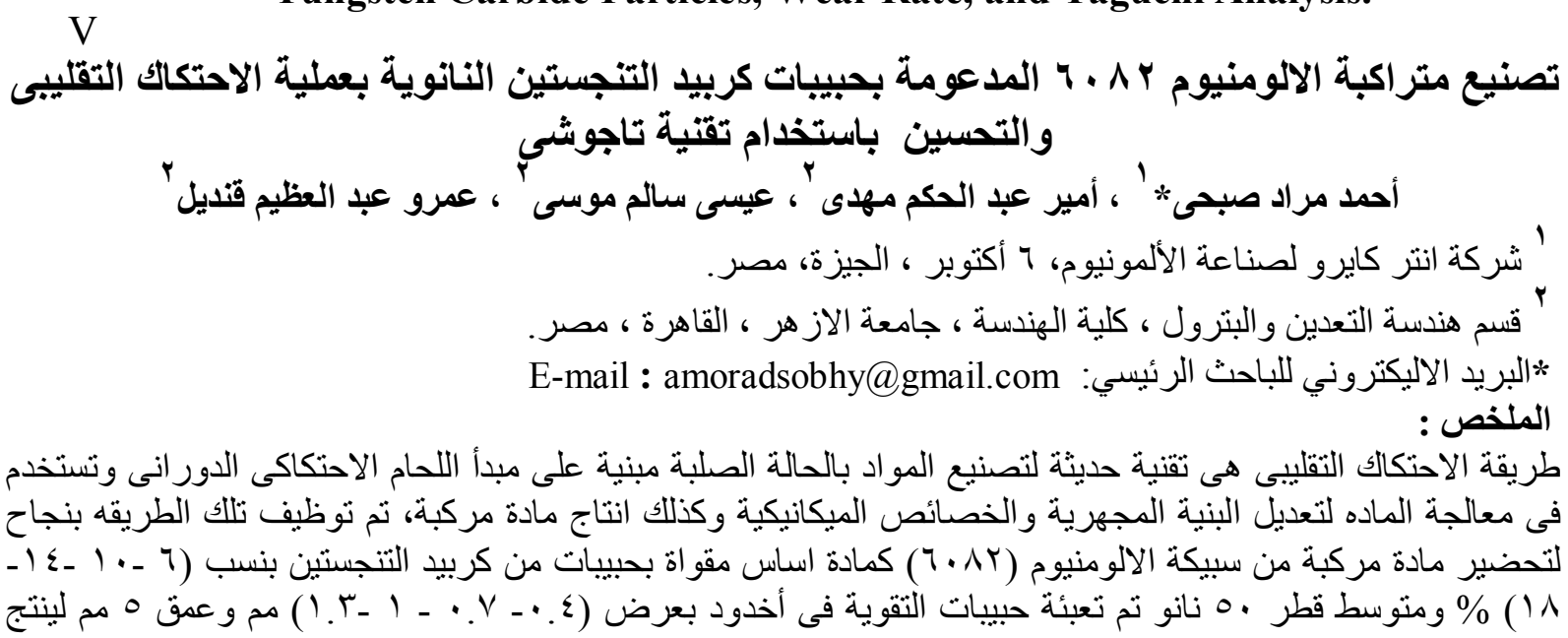




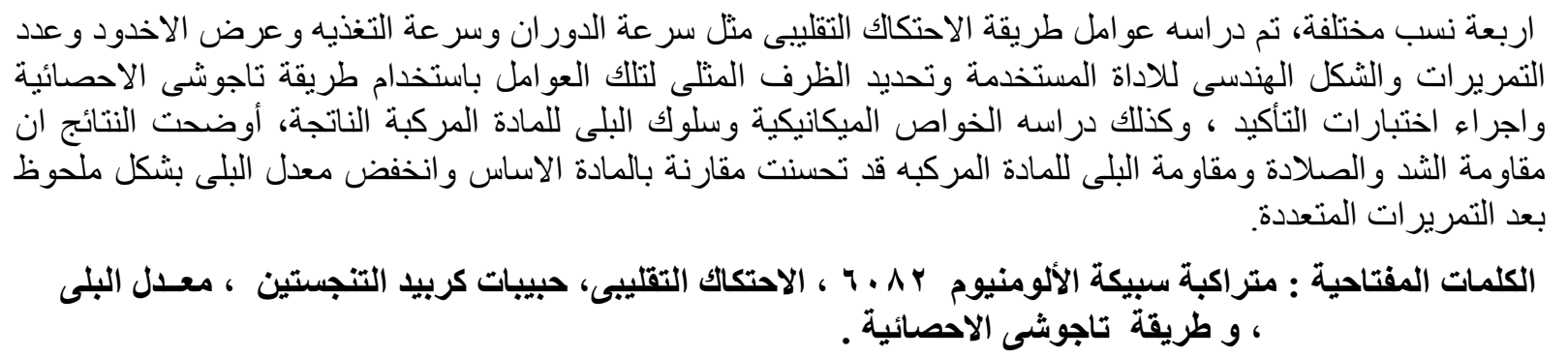

\section{INTRODUCTION}

Aluminum alloys are widely used in industrial applications, machined parts in the automotive industry, transport, structural applications in the building, marine aerospace and ship building area due to high strength to weight ratio and better corrosion resistance. AA6082 is a precipitation hardening aluminum alloy, with magnesium, silicon and manganese as the alloying elements. It has the highest strength of the 6000 series alloys due to addition amount of manganese which controls the grain structure which in turn results in a stronger alloy (M.E.J. Birch, 1986).

Aluminum matrix composites (AMCs) have become an important subject for materialists to pursue the goal of weight reduction without depreciation in desirable properties $(\mathbf{R}$. $\mathbf{L}$. Higginson, 2003). The desirable properties include high specific strength, superior wear resistance, low thermal expansion and stability at elevated temperature. AMCs are applied in components such as disc brake, engine block, piston, cylinder liners, and body panels due to those properties. A range of ceramic particles (oxides, borides, carbides and nitrides) are commonly used to reinforce various aluminum alloys to prepare AMCs (Cartney, 1989; M. Easton, 1999).

Tungsten carbide is approximately twice as stiff as steel and is double the density of steel, So it can be excellent Among the various reinforcements. Recently Friction stirring processing (FSP) appears to offer another route for the combination of ceramic particles into the metal matrix to fabricate bulk composites. Friction stir processing (FSP) is a novel solid-state method to produce AMCs and a promising method to overcome the limitations of liquid metallurgy routes (J. Muirhead, 2000). The ceramic particles are packed along the tool travel direction using various methods including vertical cylindrical holes (Dharmpal Deepak, 2013), square grooves (S. Jerome, 2012) and V shaped grooves (M.N.A. Fenoel, 2014). The frictional heat developed by the rotating shoulder and the pin plasticizes the aluminum alloy. The transverse movement of the tool causes the transportation of plasticized material from advancing side to retreading side. Subsequently the groove portion crumbles and the stirring action of the tool disperses the packed ceramic particles into the plasticized aluminum alloy. The AMCs is thus formed and forged at the back of the tool due to the applied axial force (Vipin Sharma, 2015; Mojtaba Salehi, 2014).

Taguchi's method is statically tool used for analyzing the experimental results to establish the best condition for processes, to and to predict optimal response of process parameters.

(Montgomery, 2006; Ross, 1995).

\section{EXPERIMENTAL WORK}

\subsection{Materials}

Extruded plates of aluminum alloy 6082-T6 were used as a matrix Fig.1. the chemical composition of base metal is presented in Table 1.

Table 1. Chemical composition of 6082 aluminum alloy (wt. \%)

\begin{tabular}{|c|c|c|c|c|c|c|c|c|c|c|}
\hline \multirow{2}{*}{ Element } & \multirow{2}{*}{ Si } & \multirow{2}{*}{ Mg } & \multirow{2}{*}{$\mathbf{F e}$} & \multirow{2}{*}{ Mn } & \multirow{2}{*}{$\mathrm{Cu}$} & \multirow{2}{*}{ Zn } & \multirow{2}{*}{$\mathbf{T i}$} & \multicolumn{2}{|c|}{ others } & \\
\hline & & & & & & & & each & total & \\
\hline Wt. \% & 0.90 & 1 & 0.35 & 0.65 & 0.04 & 0.001 & 0.020 & 0.05 & 0.15 & Bal \\
\hline
\end{tabular}

plates having $10 \mathrm{~mm}$ thickness are cut to size of $100 \mathrm{~mm}$ wide and $170 \mathrm{~mm}$ long perpendicular to extrusion direction. The 
plates were machined at the middle along the length direction using wire cut EDM process to create a groove for packing the WC particles, as showed in Fig. 1. The length and depth of the grooves were kept constant for all experiments which were $170 \mathrm{~mm}$ and $5 \mathrm{~mm}$, respectively. The width of the grooves was varied in four levels $(0.4,0.7,1$ and $1.3 \mathrm{~mm})$ so that the volume fraction of the reinforcement will have four levels $(6,10,14$, and 18 vol. \%), the volume fraction was estimated based on mathematical expressions reported elsewhere (R. Sathiskumar, 2013). The selected reinforcement is tungsten carbide (WC) powder particles of $99.8 \%$ purity and average particle size of $50 \mathrm{~nm}$. The SEM micrograph is depicted in Fig. 2.

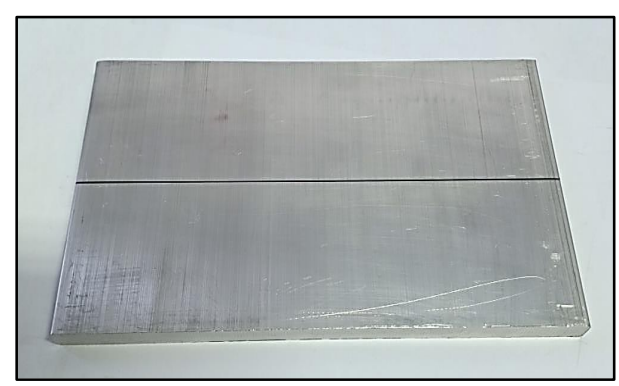

Fig.1. Workpiece material.

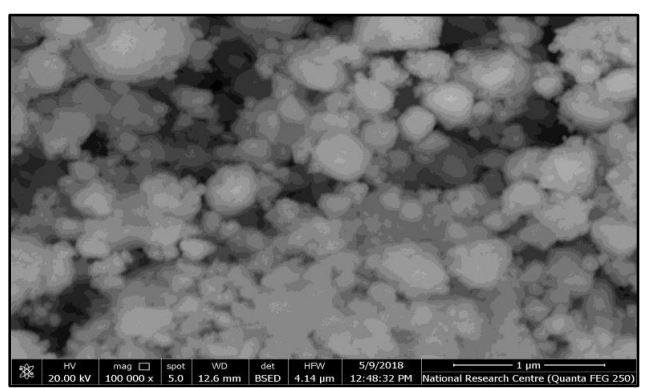

Fig. 2. SEM micrograph of WC particles

FSP tools are made of heat-treated $\mathrm{H} 13$ tool steel which were subsequently hardened to 58 HRC, with a flat shoulder of $18 \mathrm{~mm}$ diameter with concentric circles and dimensions of the tool pin were diameter of $6 \mathrm{~mm}$ and $5 \mathrm{~mm}$ length and threaded pin of $1 \mathrm{~mm}$ pitch, figure 3 shows the four different tool pin profiles and tool without pin (five tool).

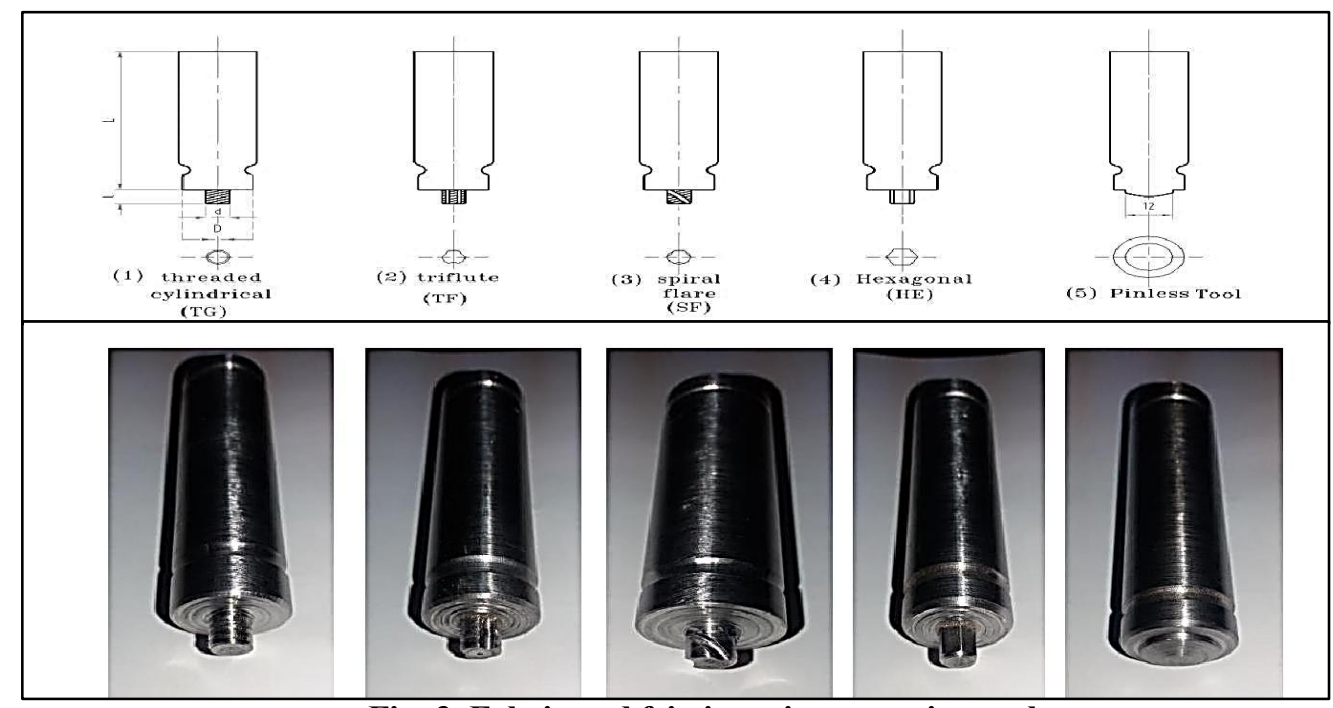

\section{2. FSP Process}

Fig. 3. Fabricated friction stir processing tools.

FSP was accomplished using a robust computer numerical controlled vertical milling machine as showed in Fig. 4.
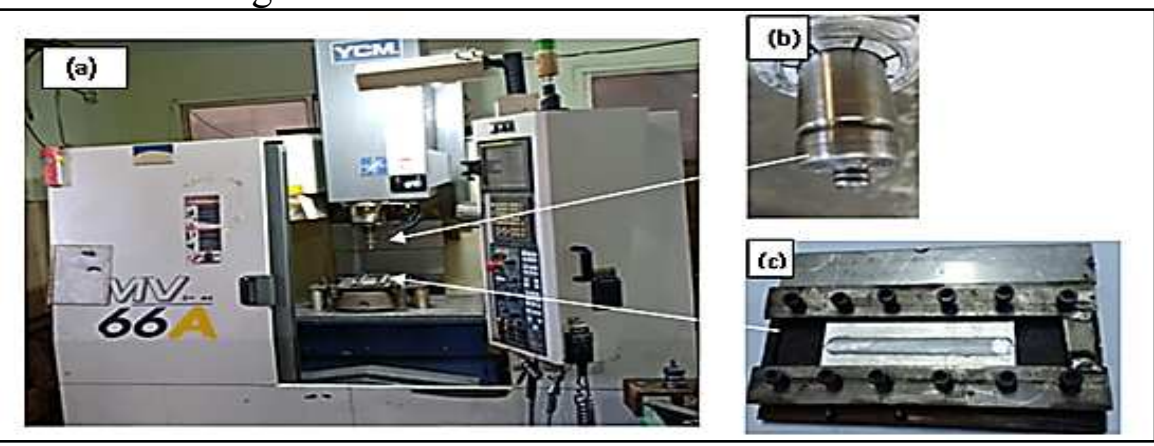

Fig. 4. FSP machine (CNC vertical milling machine) (a), (b) Fabricated FSP tool, and (c) FSP layout. The Fixture was first fixed with help of clamps on the machine bed, and then the plates were properly held in the fixture for FSP. Upon 
clamping the plates on the machine vice, the powder was packed in the groove. At first, a pin less tool was crossed along a groove with rotational speed of $1000 \mathrm{rpm}$ and a feed of $25 \mathrm{~mm} /$ min to compact particles and close the groove opening in order to avoid the spattering of WC Nano-particles during FSP as schematically illustrated in Fig. 5.

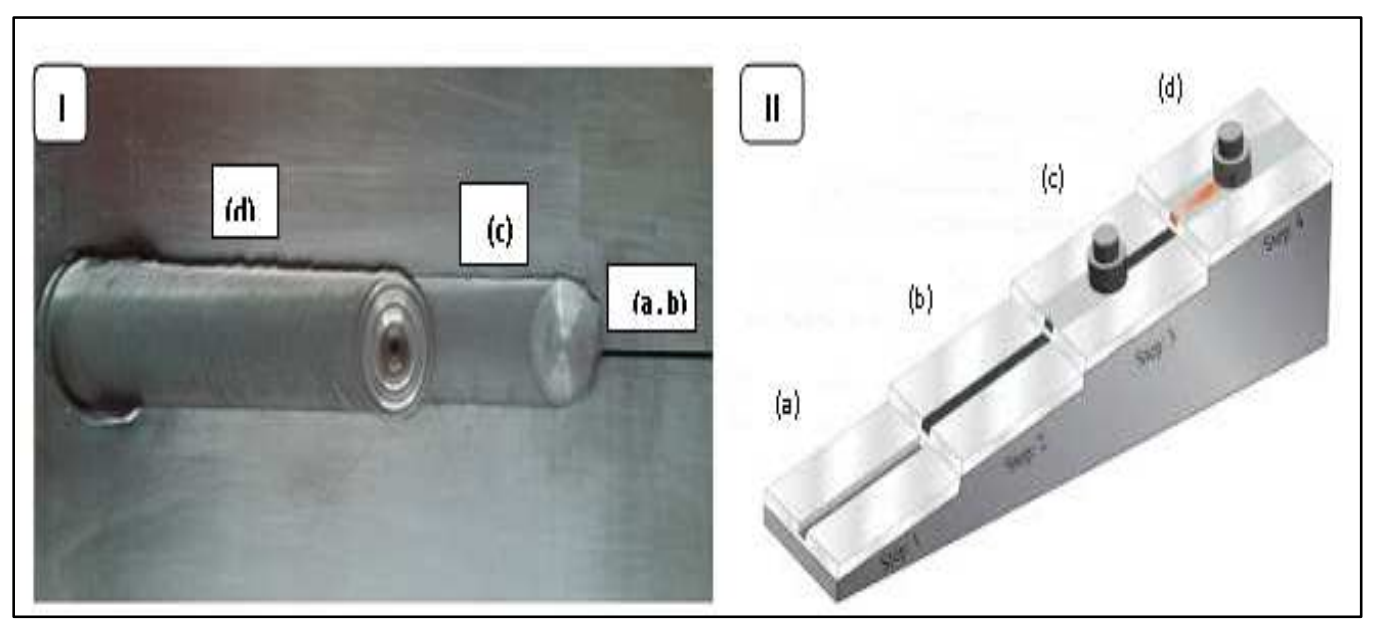

Fig. 5. FSP procedures to fabricate composite: (a) cutting a groove, (b) compacting the groove with ceramic particles, (c) processing using a painless tool and (d) processing using a tool with pin.

The process parameters and their levels shown in the Table 2. The process parameters were chosen based on literatures and author's past experience by perform a series of FSP trial runs to yield a uniform distribution of reinforcement particles across the stir zone, the process parameters were optimized using Taguchi method for single responses towards the tensile strength, wear rate and hardness the five parameters and four levels were selected and generated L16 matrix. The experimental design matrix is shown in the Table 3 . The friction stir processed plates are shown in Fig.6.

Table 2. Friction stir processing parameters and their levels

\begin{tabular}{|c|c|c|c|c|c|c|c|}
\hline \multirow[b]{2}{*}{1} & \multirow{2}{*}{$\frac{\text { Parameter }}{\text { Rotation Speed }}$} & \multirow{2}{*}{$\frac{\text { Notation }}{\mathrm{S}}$} & \multirow{2}{*}{$\frac{\text { Unit }}{\text { rpm }}$} & \multicolumn{4}{|c|}{ Levels } \\
\hline & & & & 1000 & 1200 & 1400 & 1600 \\
\hline 2 & Travel Speed & $\mathrm{F}$ & $\mathrm{mm} / \mathrm{min}$ & 40 & 60 & 80 & 100 \\
\hline 3 & Pin tools & $\mathrm{P}$ & ----- & $\mathrm{TC}$ & $\mathrm{TF}$ & $\mathrm{SF}$ & $\mathrm{HE}$ \\
\hline 4 & $\begin{array}{c}\text { Number of } \\
\text { passes }\end{array}$ & $\mathrm{N}$ & Pass & One pass & $\begin{array}{c}\text { Two } \\
\text { passes }\end{array}$ & $\begin{array}{l}\text { Three } \\
\text { passes }\end{array}$ & $\begin{array}{c}\text { Four } \\
\text { passees }\end{array}$ \\
\hline 5 & Reinforcement & $\mathrm{R}$ & $\%$ & 6 & 10 & 14 & 18 \\
\hline
\end{tabular}


Table 3. The experimental design matrix

\begin{tabular}{cccccc}
\hline Exp. $\mathbf{N}$ & Speed (S) & Feed (F) & P & N & $\begin{array}{c}\text { Reinforcement } \\
(\mathbf{R}) \%\end{array}$ \\
\hline FSP 1 & 1000 & 20 & TC & 1 & 6 \\
FSP 2 & 1000 & 40 & TF & 2 & 10 \\
\hline FSP 3 & 1000 & 60 & SF & 3 & 14 \\
FSP 4 & 1000 & 80 & HE & 4 & 18 \\
FSP 5 & 1200 & 20 & TF & 3 & 18 \\
FSP 6 & 1200 & 40 & TC & 4 & 14 \\
FSP 7 & 1200 & 60 & HE & 1 & 10 \\
FSP 8 & 1200 & 80 & SF & 2 & 6 \\
FSP 9 & 1400 & 20 & SF & 4 & 10 \\
FSP 10 & 1400 & 40 & HE & 3 & 6 \\
FSP 1 & 1400 & 60 & TC & 2 & 10 \\
FSP 12 & 1400 & 80 & TF & 1 & 14 \\
\hline FSP 13 & 1600 & 20 & HE & 2 & 14 \\
FSP 14 & 1600 & 40 & SF & 1 & 18 \\
\hline FSP 15 & 1600 & 60 & TF & 4 & 6 \\
\hline FSP 16 & 1600 & 80 & TC & 3 & 10 \\
\hline
\end{tabular}

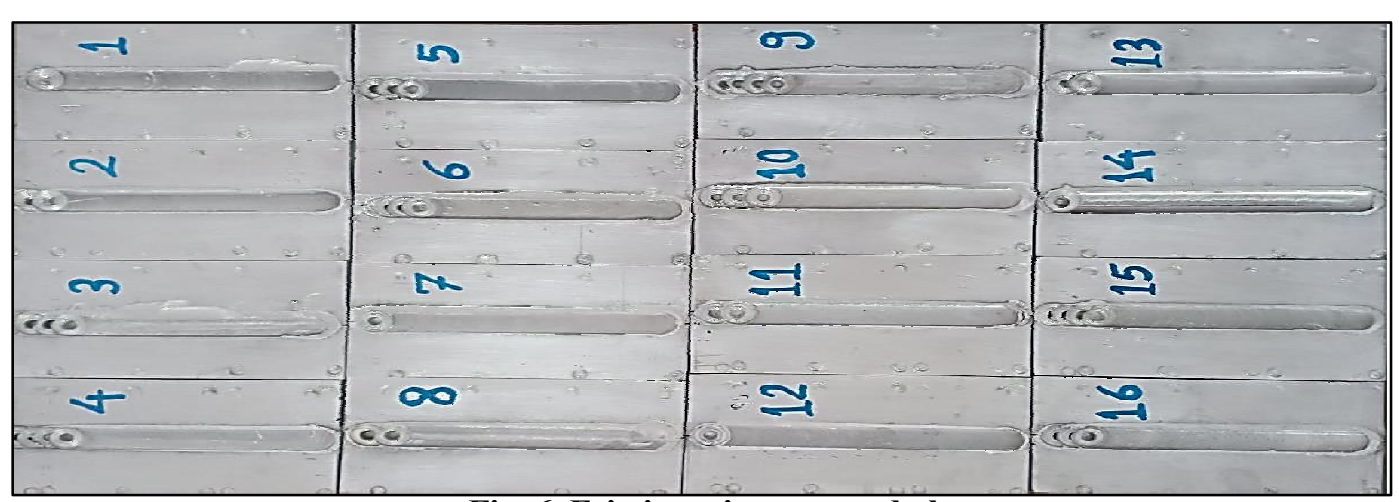

Fig. 6. Friction stir processed plates.

\subsection{Specimens sampling and testing}

After FSP, the samples were cut for examination of, hardness, tensile strength and wear rate from the stir zone (SZ) as schematically illustrated in Fig. 7, using wire electric discharge machining

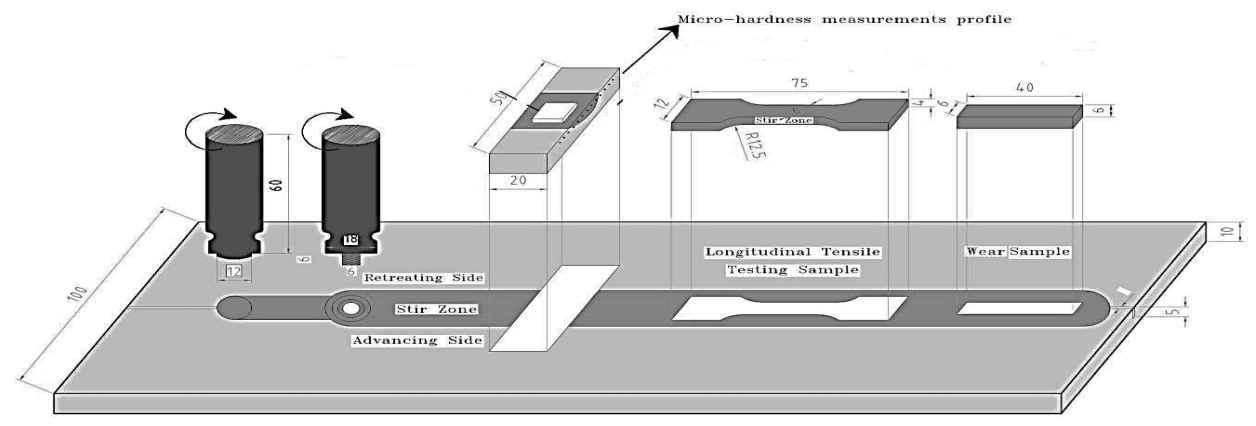

Fig. 7. Schematic illustration of the procedure for cutting. 
The microhardness was measured at several locations at an interval of $3 \mathrm{~mm}$, with a load of $200 \mathrm{~g}$ by the Vickers Hardness Tester.

Mini tensile specimens measuring $25 \mathrm{~mm}$ gauge length, $6 \mathrm{~mm}$ width and $4 \mathrm{~mm}$ thickness as per ASTM E8 standards have been prepared from the FSP zone which is parallel to the composite direction using wire EDM. The tensile test was performed by a computercontrolled universal test machine shown in Fig 8.

The wear rate test was conducted at room temperature by the pin-on-disk wear system (DUCOM TR20-LE) according to the ASTMG99 04 standard. The specimen dimensions for wear test are $40 \times 6 \times 5 \mathrm{~mm}$, where its polished surface was placed against the rotating disk which made of hardened chromium steel (HRC 62). Where it carried out at a constant speed of $1.66 \mathrm{~m} / \mathrm{sec}$, sliding load of $5 \mathrm{~kg}$ and a total sliding distance of $3000 \mathrm{~m}$ for $30 \mathrm{~min}$. An electron weighing scale with an accuracy of $0.001 \mathrm{mg}$ was used to determine the samples weight losses value.
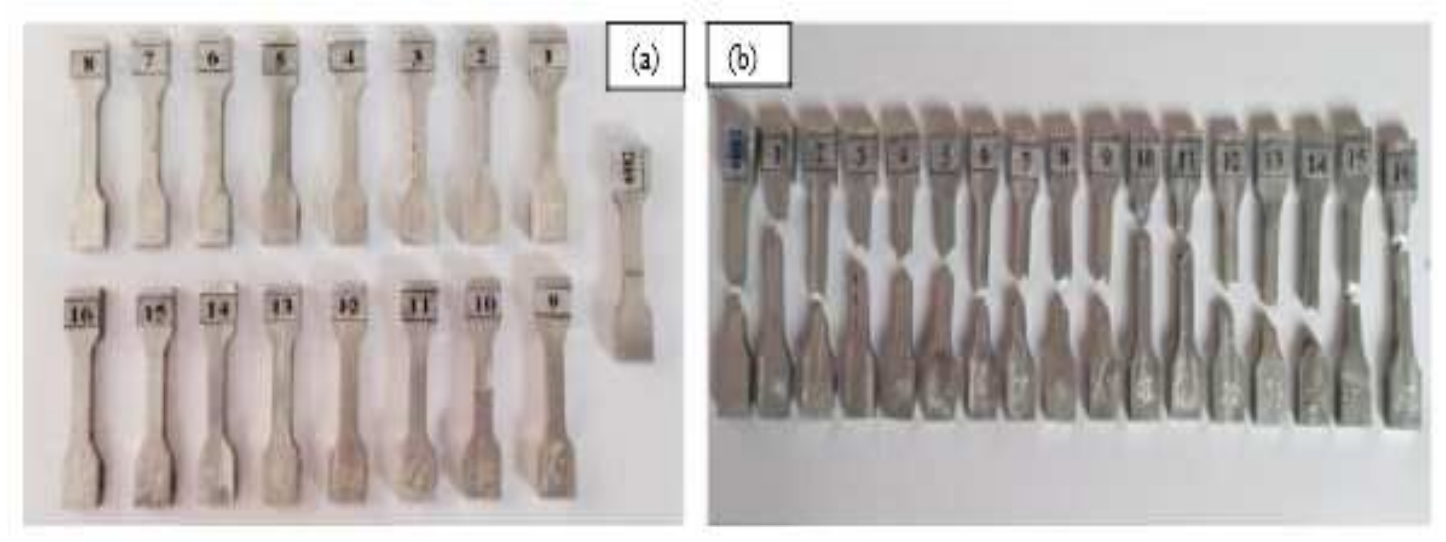

Fig. 8. Typical Tensile Specimens (a), (b) Typical Tensile Tested Specimen

\section{RESULTS AND DISCUSSION}

\subsection{Single response optimization using Taguchi method}

The Taguchi's technique is used for single response optimization. The ultimate tensile strength (UTS), hardness, and wear rate were analyzed to optimize the processing parameters. The larger the better criterion was selected for both ultimate tensile strength (UTS), and hardness responses the smaller the better criterion was selected for wear rate to maximize responses.

\subsubsection{Analysis of Signal-to-Noise Ratio}

The mechanical properties, and wear rate were evaluated and presented in Table 4 . The $\mathrm{S} / \mathrm{N}$ ratio was calculated using the equation 5 and tabulated in the Table 4 . The term signal indicates the desirable value for output characteristic and noise represents the undesirable value for the output

$\mathrm{S} / \mathrm{N}=-10 \log 10\left(1 / \mathrm{n} \sum 1 / \mathrm{y} 2\right)(5)$

Where $\mathrm{y}$ is the observed data and $\mathrm{n}$ is the number of observations. All the calculations are performed using Minitab 17 software. 
Table 4. Process parameters, experimental results and $\mathrm{S} / \mathrm{N}$ ratio

\begin{tabular}{|c|c|c|c|c|c|c|c|c|c|c|c|}
\hline & \multicolumn{5}{|c|}{ Process Parameters } & \multicolumn{3}{|c|}{$\begin{array}{c}\text { Experimental } \\
\text { Results }\end{array}$} & \multicolumn{3}{|c|}{$\mathrm{S} / \mathrm{N}$ ratio } \\
\hline & $\mathrm{S}$ & $\mathrm{F}$ & $\mathrm{P}$ & $\mathrm{N}$ & $\mathrm{R} \%$ & UTS & $\mathrm{H}$ & $\begin{array}{l}\text { Wear } \\
\text { Rate }\end{array}$ & $\begin{array}{l}\mathrm{S} / \mathrm{N} \\
\text { for } \\
\text { UTS }\end{array}$ & $\begin{array}{l}\mathrm{S} / \mathrm{N} \\
\text { for } \mathrm{H}\end{array}$ & $\begin{array}{l}\mathrm{S} / \mathrm{N} \text { for } \\
\text { Wear }\end{array}$ \\
\hline FSP 1 & 1000 & 20 & $\mathrm{TC}$ & 1 & 6 & 231 & 122 & 0.0023 & 47.28 & 41.72 & 52.65 \\
\hline FSP 2 & 1000 & 40 & $\mathrm{TF}$ & 2 & 10 & 285 & 126 & 0.0016 & 49.10 & 42.0 & 55.59 \\
\hline FSP 3 & 1000 & 60 & SF & 3 & 14 & 207 & 105 & 0.0020 & 46.34 & 40.42 & 53.97 \\
\hline FSP 4 & 1000 & 80 & $\mathrm{HE}$ & 4 & 18 & 295 & 113 & 0.0006 & 49.41 & 41.06 & 63.60 \\
\hline FSP 5 & 1200 & 20 & TF & 3 & 18 & 295 & 103 & 0.0010 & 49.41 & 40.25 & 60.0 \\
\hline FSP 6 & 1200 & 40 & $\mathrm{TC}$ & 4 & 14 & 283 & 123 & 0.0016 & 49.04 & 41.79 & 55.5 \\
\hline FSP 7 & 1200 & 60 & $\mathrm{HE}$ & 1 & 10 & 241 & 101 & 0.0020 & 47.64 & 40.08 & 53.97 \\
\hline FSP 8 & 1200 & 80 & SF & 2 & 6 & 256 & 105 & 0.0033 & 48.17 & 40.42 & 49.62 \\
\hline FSP 9 & 1400 & 20 & SF & 4 & 10 & 238 & 132 & 0.0023 & 47.53 & 42.41 & 52.76 \\
\hline FSP10 & 1400 & 40 & $\mathrm{HE}$ & 3 & 6 & 286 & 105 & 0.0013 & 49.14 & 40.42 & 57.72 \\
\hline FSP11 & 1400 & 60 & $\mathrm{TC}$ & 2 & 18 & 298 & 111 & 0.0010 & 49.48 & 40.90 & 60.0 \\
\hline FSP12 & 1400 & 80 & $\mathrm{TF}$ & 1 & 14 & 238 & 115 & 0.0006 & 47.53 & 41.21 & 63.6 \\
\hline FSP13 & 1600 & 20 & $\mathrm{HE}$ & 2 & 14 & 240 & 107 & 0.0013 & 47.62 & 40.58 & 57.7 \\
\hline FSP14 & 1600 & 40 & SF & 1 & 18 & 152 & 101 & 0.0056 & 43.66 & 40.08 & 45.03 \\
\hline FSP15 & 1600 & 60 & $\mathrm{TF}$ & 4 & 6 & 307 & 101 & 0.0023 & 49.75 & 40.08 & 52.76 \\
\hline FSP16 & 1600 & 80 & $\mathrm{TC}$ & 3 & 10 & 303 & 107 & 0.0030 & 49.64 & 40.58 & 50.45 \\
\hline AA6082 & & & & & & 246 & 95 & 0.0077 & & & \\
\hline
\end{tabular}

The mean $\mathrm{S} / \mathrm{N}$ ratio was estimated and presented in the Table 6 the table includes ranks based on Delta value (the highest average of each factor minus the lowest average of the same); rank 1 is assigned to the parameter with highest Delta value, rank 2 to second highest Delta value.

Table 5. Response for S/N Ratios

\begin{tabular}{|c|c|c|c|c|c|}
\hline \multicolumn{6}{|c|}{ Hardness } \\
\hline & $\mathrm{S}$ & $\mathrm{F}$ & $P$ & $\mathrm{~N}$ & $\mathrm{R}$ \\
\hline 1 & 41.30 & 41.25 & 41.25 & 40.78 & 40.67 \\
\hline 2 & 40.64 & 41.08 & 40.89 & 40.98 & 41.27 \\
\hline 3 & 41.24 & 40.38 & 40.84 & 40.42 & 41.01 \\
\hline 4 & 40.34 & 40.82 & 40.54 & 41.34 & 40.58 \\
\hline $\begin{array}{l}\text { Delta } \\
\text { (Max- } \\
\text { Min) }\end{array}$ & 0.97 & 0.87 & 0.71 & 0.92 & 0.70 \\
\hline Rank & 1 & 3 & 4 & 2 & 5 \\
\hline
\end{tabular}

\begin{tabular}{cccccc}
\hline \multicolumn{6}{c}{ UTS } \\
\hline \multicolumn{1}{c}{$\mathrm{S}$} & $\mathrm{F}$ & $\mathrm{p}$ & $\mathrm{N}$ & $\mathrm{R}$ \\
\hline 1 & 48.04 & 47.97 & 48.87 & 46.53 & 48.59 \\
\hline 2 & 48.57 & 47.74 & 48.95 & 48.60 & 48.48 \\
\hline 3 & 48.43 & 48.31 & 46.43 & 48.64 & 47.64 \\
\hline 4 & 47.67 & 48.69 & 48.46 & 48.94 & 48.00 \\
\hline $\begin{array}{c}\text { Delta } \\
\text { Max- }\end{array}$ & 0.90 & .095 & 2.52 & 2.41 & 0.95 \\
Min) & & & & & \\
\hline Rank & $\mathbf{5}$ & $\mathbf{3}$ & $\mathbf{l}$ & $\mathbf{2}$ & $\mathbf{4}$ \\
\hline
\end{tabular}

\begin{tabular}{cccccc}
\hline \multicolumn{7}{c}{ Wear rate } \\
\hline & $\mathrm{S}$ & $\mathrm{F}$ & $\mathrm{p}$ & $\mathrm{N}$ & $\mathrm{R}$ \\
\hline 1 & 56.46 & 55.78 & 54.68 & 53.82 & 53.19 \\
\hline 2 & 54.80 & 53.49 & 57.99 & 55.74 & 53.20 \\
\hline 3 & 58.52 & 55.18 & 50.35 & 55.54 & 57.73 \\
\hline 4 & 51.50 & 56.83 & 58.26 & 56.18 & 57.16 \\
\hline $\begin{array}{l}\text { Delta } \\
\text { Max- }\end{array}$ & 7.03 & 3.34 & 7.90 & 2.37 & 4.53 \\
Min) & & & & & \\
\hline Rank & $\mathbf{2}$ & $\mathbf{4}$ & $\mathbf{l}$ & $\mathbf{5}$ & $\mathbf{3}$ \\
\hline
\end{tabular}


The $\mathrm{S} / \mathrm{N}$ ratios and response table for all individual responses are shown in Fig. 9. Based on the mean response table of $\mathrm{S} / \mathrm{N}$ ratio, an optimal level for each parameter was identified with a larger value of $\mathrm{S} / \mathrm{N}$ ratio for both ultimate tensile strength (UTS), hardness, and a smaller value of $\mathrm{S} / \mathrm{N}$ ratio for Wear rate.
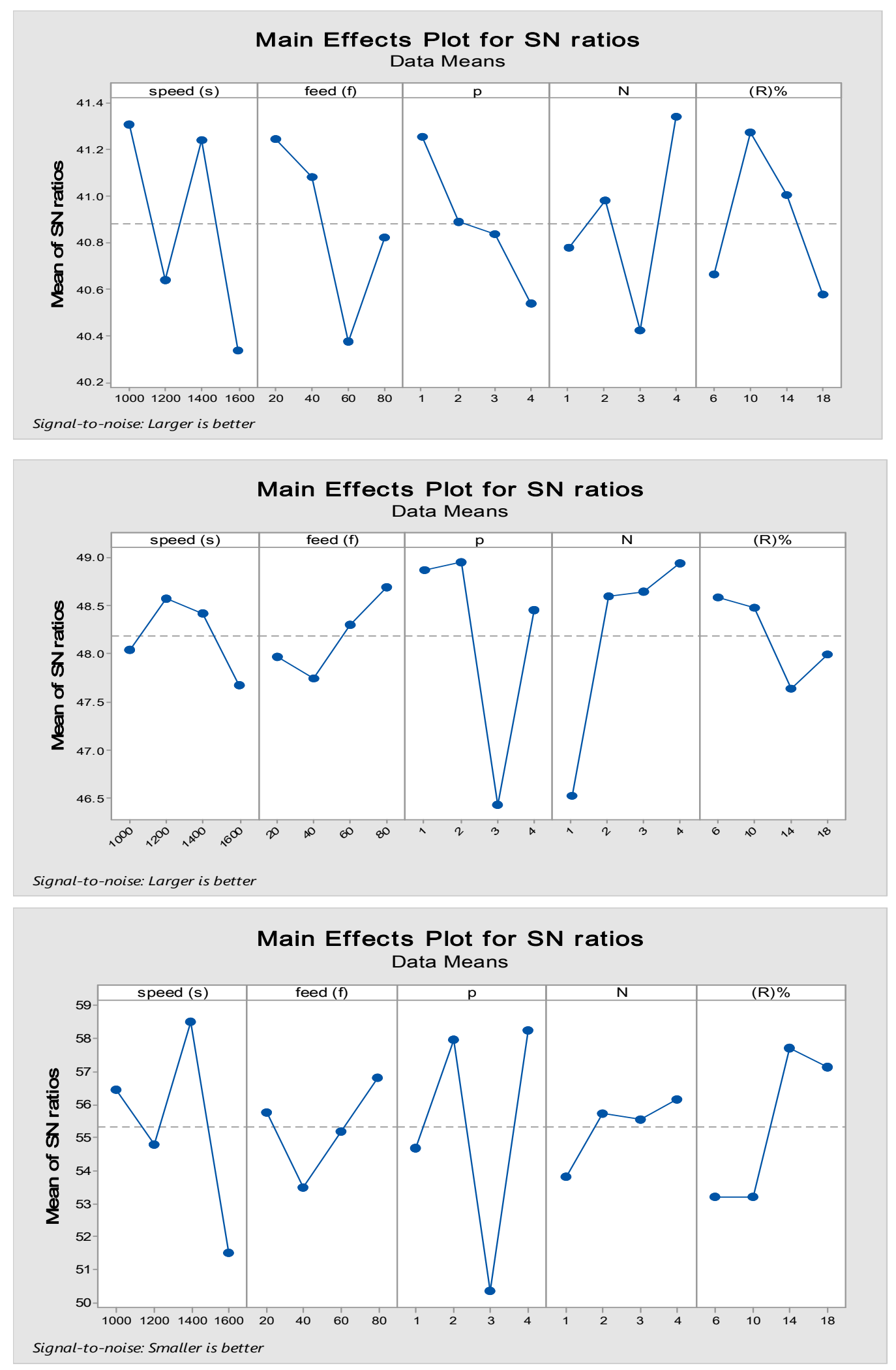

Fig. 9. The Main Effects plots for S/N Ratios. 


\subsubsection{Confirmation Tests}

The optimal value of Taguchi is estimated from the equation (6) and tabulated in the Table 6.

$$
{ }^{\vee} \text { predicted }=\mathrm{\gamma} m+\sum_{i=0}^{n=16}\left({ }^{2} i-\gamma m\right)
$$

Where ${ }^{\mathrm{r}} \mathrm{m}$ is the mean of the response, $\mathrm{n}$ is the number of experiments, ${ }^{\mathrm{r}} \mathrm{i}$ is the value at mean level for optimal parameter. The optimum level of the process parameters is the level with the highest $\mathrm{S} / \mathrm{N}$ ratio and predicted the optimal values for UTS, hardness and wear rate. The confirmation was carried out by taking the optimal process parameters. The tested mechanical properties and wear rate of experimental values are less than $10 \%$ variation compared to Predicted values.

\begin{tabular}{|c|c|c|c|}
\hline Quality Characteristic & Optimal Parameters & Predicted Value & $\begin{array}{c}\text { Experimental } \\
\text { Value }\end{array}$ \\
\hline $\begin{array}{l}\text { 1.Taguchi optimization } \\
\text { for UTS } \\
\text { (MPa) }\end{array}$ & $\begin{array}{c}\text { Speed }=1200 \mathrm{rpm}, \\
\text { Feed }=80 \mathrm{~mm} / \mathrm{min} \\
\text { Pin Profile }=\mathrm{TF} \\
\text { Number of Passes }=4 \\
\text { Reinforcement }=6 \%\end{array}$ & $335.38 \mathrm{MPa}$ & $319.48 \mathrm{MPa}$ \\
\hline $\begin{array}{c}\text { 2.Taguchi optimization } \\
\text { for Hardness } \\
(\mathrm{Hv})\end{array}$ & $\begin{array}{c}\text { Speed }=1000 \mathrm{rpm}, \\
\text { Feed }=20 \mathrm{~mm} / \mathrm{min} \\
\text { Pin Profile }=\mathrm{TC} \\
\text { Number of Passes }=4 \\
\text { Reinforcement }=10 \%\end{array}$ & $137.75 \mathrm{Hv}$ & $126.86 \mathrm{Hv}$ \\
\hline $\begin{array}{l}\text { 3.Taguchi optimization } \\
\text { for Wear Rate } \\
(\mathrm{mg} / \mathrm{m})\end{array}$ & $\begin{array}{c}\text { Speed }=1400 \mathrm{rpm}, \\
\text { Feed }=80 \mathrm{~mm} / \mathrm{min} \\
\text { Pin Profile }=\mathrm{HE} \\
\text { Number of Passes }=4 \\
\text { Reinforcement }=14 \%\end{array}$ & $0.00036 \mathrm{mg} / \mathrm{m}$ & $0.00039 \mathrm{mg} / \mathrm{m}$ \\
\hline
\end{tabular}

Table 6. Validation of Optimal Results.

\subsection{Mechanical properties}

The mechanical properties such as Ultimate tensile strength and hardness were evaluated. It was observed that UTS increased with decrease of speed from $1600 \mathrm{rpm}$ to $1000 \mathrm{rpm}$, and increasing feed of the tool from $20 \mathrm{~mm} / \mathrm{min}$ to $80 \mathrm{~mm} / \mathrm{min}$ This may due to higher the heat input with the higher speed and lower feed which cause more softening effect in the stir zone because of stirring action of the tool pin. The highest value of Hardness of $132 \mathrm{HV}$ which $28 \%$ higher than the base metal. This may be due to presence of reinforced particles and micro structural changes like DRX induced by FSP and orowan strengthening and the movement of dislocations due to presence of reinforcement are responsible for improvement of hardness. By increasing the number of passes from 1 to 4, the UTS and hardness of composites increased.

\subsection{Sliding wear behavior of AA6082/WC AMCs}

The rate of wear was measured to be $0.0077 \mathrm{mg} / \mathrm{m}$ at 0 vol. $\%$ and $0.00066 \mathrm{mg} / \mathrm{m}$ at 18 vol.\%. The greater wear behavior of the AMC can be attributed to its superior micro hardness value; this was achieved due to the presence and uniform distribution of WC particles which in turn refined the AMC matrix grains. weight loss is inversely proportional to the hardness of the AMC. because, the resistance to remove material during sliding increases. fraction of WC particles is covered with numerous debris due to the formation of fine wear-debris. as the volume fraction of WC is increased to $14 \%$. The reinforcement of WC particles offers resistance to the movement of plasticized matrix and reduces the contact areas. 


\section{CONCLUSIONS}

The conclusions derived from this study can be summarized as follows:

1. The AA6082/WC (6-10-14-18) \% metal matrix composite was successfully fabricated via friction stir processing.

2. The L16 Taguchi orthogonal designed experiments of FSP on AA6082 AMCs were successfully conducted for optimization The FSP process parameters to maximize the tensile strength, microhardness and wear rate of AA6082 AMCs, and the prediction of the Taguchi design approach was in good agreement with the experimental result and lies within the $10 \%$ predicted value.

3. The Composite produced by FSP significantly improved the dry sliding wear resistance of the Al 6082 alloy

4. Multi-pass FSP using 2,3 and 4 passes consistently improves tensile properties in addition to hardness and wear resistance.

5. The optimum tensile strength is observed at rotational speed $1200 \mathrm{rpm}$, feed 80 $\mathrm{mm} / \mathrm{min}$, with TF pin profile, at four passes and $6 \% \mathrm{WC}$.

6. The optimum hardness value is observed at rotational speed $1000 \mathrm{rpm}$, feed 20 $\mathrm{mm} / \mathrm{min}$, with TC pin profile, at four passes and $10 \% \mathrm{WC}$.

7. The minimum wear rate value is observed at rotational speed $1400 \mathrm{rpm}$, feed 80 $\mathrm{mm} / \mathrm{min}$, with HE pin profile, at four passes and 14\% WC.

\section{REFERENCES}

1. Cartney, M. C. (1989). Grain refining of aluminium and its alloys using inoculants. International materials Reviews, 247.

2. Dharmpal Deepak, R. S. (2013). Preparation of 5083 Al-Sic surface composite by FSP and its mechanical characterization. International Journal of Mechanical Engineering, 12-17.

3. J. Muirhead, J. C. (2000). Quantitative aspects of grain size measurement. Materials Science Technology, 16-19.

4. M. Easton, a. D. (1999). Grain Refinement of Aluminum Alloys. Metallurgical and Materials Transactions, 1613.

5. M.E.J. Birch, P. F. (1986). Aluminium Technology. London: Institute of Metals.

6. M.N.A. Fenoel, A. S. (2014). Characterization of oxide dispersion strengthened copper based materials developed by frictio stir processing. Materials and Design, 343-357.

7. Mojtaba Salehi, H. F. (2014). Fabrication and characterization of functionally graded $\mathrm{Al}-\mathrm{SiC}$ nanocomposite by using a novel multistep friction stir processing. Materials and Design, 419-426.

8. Montgomery, D. C. (2006). Design and analysis of experiments. New York: Wiley .

9. R. L. Higginson, a. M. (2003). Worked examples in quantitative. London: Maney.

10. R. Sathiskumar, N. M. (2013). Characterization of boron carbide particulate reinforced in situ copper surface composites synthesized using friction stir processing. Materials Characterization, 16-27.

11. Ross, P. J. (1995). Taguchi techniques for quality engineering: loss function, orthogonal experiments, parameter and tolerance design. New York: Mc Graw-Hill Professional.

12. S. Jerome, S. G. (2012). Influence of microstructure and experimental parameter on mechanical and wear properties of Al-TiC surface composite by FSP. journal of Minerals and Materials Characterization and Engineering, 493-507.

13. Vipin Sharma, U. P. (2015). Surface composites by friction stir processing: A review. Journal of Materials Processing Technology, 117-134. 